\title{
Design and Implementation of Multiband Microstrip Patch Antenna for Wireless Applications
}

\author{
L. Prasad, B. Ramesh, K.S.R. Kumar ${ }^{3}$, K.P. Vinay \\ Raghu Engineering College, Visakhapatnam, India
}

\begin{abstract}
Multiband phased array antennas are required for today's multi-function communication applications. Generally Microstrip antenna arrays like Kotch array, Sierpinski array are used, but in some circuits where space is limited, arrays are not used. Therefore, to achieve the multiband operation with limited space, an antenna is designed with E-shaped in combination with split ring resonator to achieve the multiband operation. The simulation and experimental results show that the proposed antenna operates at four different frequencies, $1.8 \mathrm{GHz}, 3.6 \mathrm{GHz}, 4.53 \mathrm{GHz}$ and $5.73 \mathrm{GHz}$, which can be used for different wireless applications like GSM $1800(1.71-1.78 \mathrm{GHz})$, Wi-MAX $(3.4-3.69 \mathrm{GHz}) \quad$-IEEE 802.16 standards, Wi-Fi/WLAN $(5.15-5.82 \mathrm{GHz})$. All the simulation results like resonant frequency, return loss, radiation patterns and fabricated antenna measured result is presented in this paper. The antenna is simulated using CST 2014 software.
\end{abstract}

\section{Introduction}

In the present generation wireless communication systems are rapidly developing due to increasing demand for the mobile equipment which is to be connected with different devices operating at multiple frequencies [1]. Multiband antenna plays crucial role in wireless communication systems as it can operate in multiple frequency bands for different wireless applications like Global System for Mobile communication (GSM), Wireless Local Area Network (WLAN), and Worldwide Interoperability for Microwave Access (Wi-MAX), and Wireless Fidelity (Wi- Fi).

The advantage of multiband antenna is their ability to integrate multiple frequency bands in a single antenna which makes the design and operation more complex than single and dual band antennas. From literature [2-3], the Fractal antenna arrays like Kotch array, Sierpinski array are also used to achieve the multiband operations. But, the Fractal antennas increase the design complexity. Microstrip patch antenna is a well suited device for wireless communications which can be easily integrated with microwave circuits because of their low volume, thin profile, light weight and low cost, which can work at multiple frequencies[1]. Hence, multiband Microstrip patch antenna is of great concern nowa-days.

\section{Antenna Design}

The proposed antenna is designed using FR4 substrate with a thickness of $1.6 \mathrm{~mm}$. The dielectric constant of the FR4 substrate is 4.4. The dimensions of the ground plane and the substrate are the same, i.e. $(70 \times 60 \mathrm{~mm})$. The dimensions of the patch are taken as $(35 \times 30 \mathrm{~mm})$. The front view and side view of the designed antenna and fabricated antenna are shown in Figure 1(a), (b) \&(c).

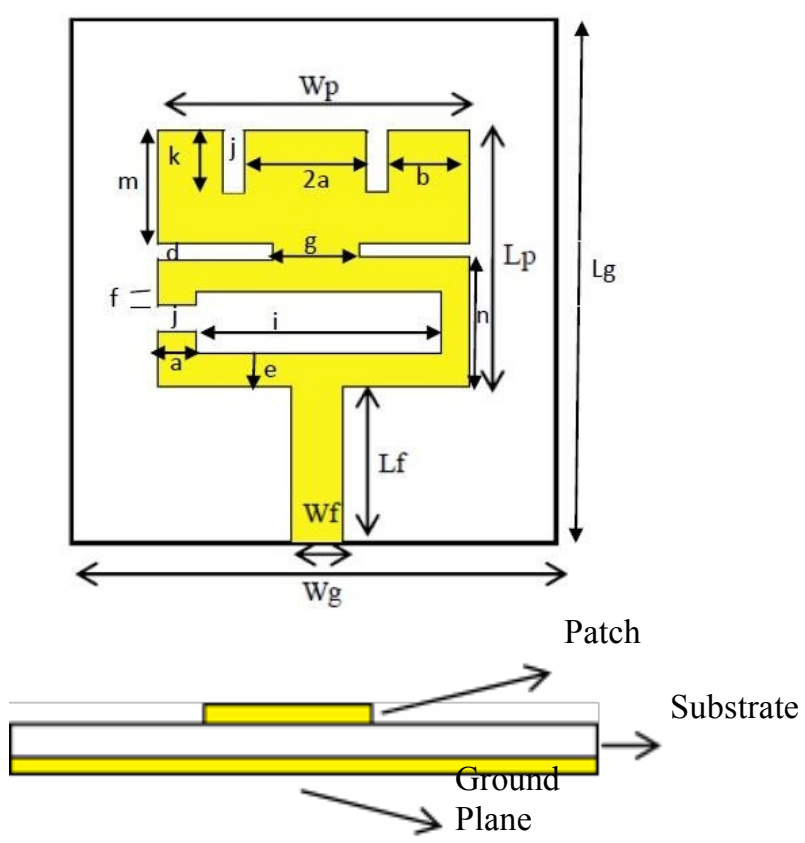

(b) Side view.

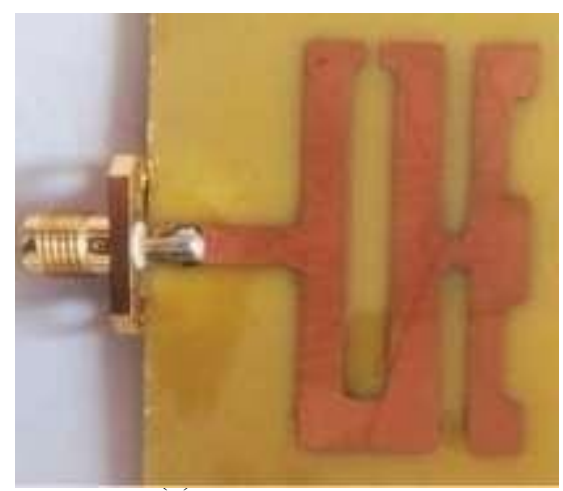

Figure 1: Geometry of the Antenna 
The antenna is designed and simulated using Computer Simulation Technology tool. Slots are made in the patch to obtain multiband characteristics [4-6]. The dimensions of the antenna are tabulated as shown in Table 1.

Table 1. Values of different parameters.

\begin{tabular}{|c|c|c|c|}
\hline S.No & Parameter & Description & Value (mm) \\
\hline 1 & $\mathrm{Wg}$ & $\begin{array}{l}\text { Width of the ground } \\
\text { plane }\end{array}$ & 60 \\
\hline 2 & $\mathrm{Lg}$ & $\begin{array}{c}\text { Length of the ground } \\
\text { plane }\end{array}$ & 70 \\
\hline 3 & $\mathrm{~W}_{\mathrm{p}}$ & Width of the patch & 30 \\
\hline 4 & $\mathrm{Lp}$ & Length of the patch & 35 \\
\hline 5 & Wf & Width of the feed & 3 \\
\hline 6 & Lf & Length of the feed & 17.5 \\
\hline 7 & $\mathrm{a}$ & $\begin{array}{l}\text { Width of the SRR \& } \\
\text { center arm of E }\end{array}$ & 4 \\
\hline 8 & $\mathrm{~b}$ & Width of the E-arms & 7 \\
\hline 9 & $\mathrm{~d}$ & Gap between E \& SRR & 1 \\
\hline 10 & e & $\begin{array}{c}\text { Width of the SRR- } \\
\text { shaped slot }\end{array}$ & 5.5 \\
\hline 11 & $\mathrm{f}$ & Length of SRR arm & 1 \\
\hline 12 & g & $\begin{array}{c}\text { Rectangular junction } \\
\text { width between E \& } \\
\text { SRR } \\
\end{array}$ & 5 \\
\hline 13 & $\mathrm{i}$ & $\begin{array}{l}\text { Length of the SRR- } \\
\text { shaped slot }\end{array}$ & 22 \\
\hline 14 & $\mathrm{j}$ & Slot length of SRR & 3 \\
\hline 15 & $\mathrm{k}$ & $\begin{array}{c}\text { Length of the slot in E- } \\
\text { shape }\end{array}$ & 12 \\
\hline 16 & $\mathrm{~m}$ & Length of E & 16.5 \\
\hline 17 & $\mathrm{n}$ & Length of SRR & 16.5 \\
\hline
\end{tabular}

Microstrip line feeding is used for the proposed antenna as it is easy to fabricate. The length and width of the slots determine the resonant frequencies of the antenna [7-12]. By changing the proportions of the length and width of the slots multiband characteristics may change. The optimized parameters of the slots are chosen for fabrication.

\section{Simulation Results}

By simulating the design, four different resonant frequencies are obtained as indicated in figure 2. The four resonant frequencies are $1.8 \mathrm{GHz}, 3.6 \mathrm{GHz}, 4.53 \mathrm{GHz}$ and $5.73 \mathrm{GHz}$ respectively.

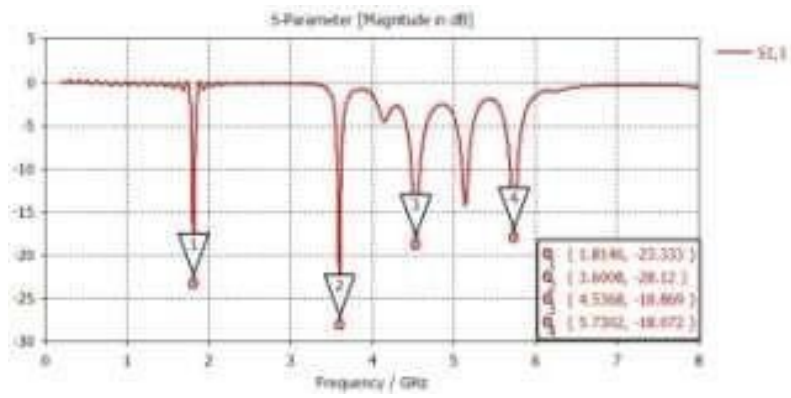

Figure 2: $\mathrm{S}_{11}$ parameter of the designed antenna.
For first resonating frequency i.e. for $1.8 \mathrm{GHz}$, the return loss is $-23.33 \mathrm{~dB}$. For second frequency i.e. for $3.6 \mathrm{GHz}$ the return loss is about $-28.105 \mathrm{~dB}$, the third resonant frequency is obtained at $4.5 \mathrm{GHz}$, where the return loss is about $-18.8 \mathrm{~dB}$.

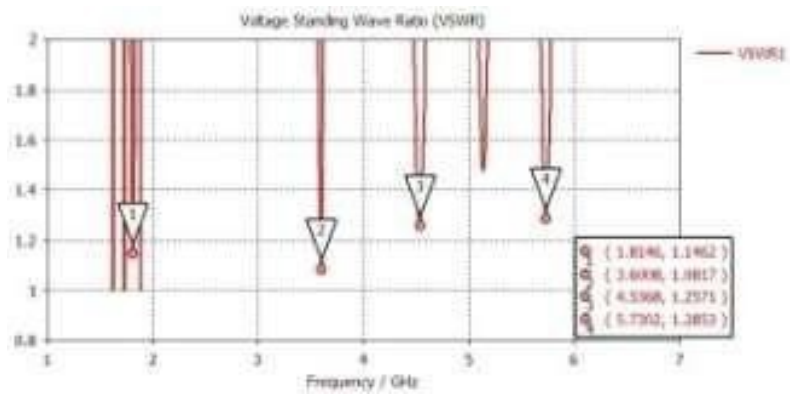

Figure 3.VSWR plot of the simulated antenna.

The fourth resonating frequency is obtained at $5.73 \mathrm{GHz}$ with a return loss of $-18.072 \mathrm{~dB}$. Figure 3 shows the VSWR plot of the designed antenna.

Ideally, the VSWR ranges between 1-2 which has been achieved for all four frequencies, i.e. at $1.8 \mathrm{GHz}, 3.6 \mathrm{GHz}$, $4.53 \mathrm{GHz}$ and $5.73 \mathrm{GHz}$ respectively. The VSWR values at $1.8 \mathrm{GHz}, 3.6 \mathrm{GHz}, 4.53 \mathrm{GHz}$ and $5.73 \mathrm{GHz}$ is $1.1493,1.0817$, 1.2572 and 1.2855 respectively.

The radiation pattern of the antenna at different frequencies is depicted in figure 4 . It can be seen that the radiation patterns are omnidirectional in E-plane.

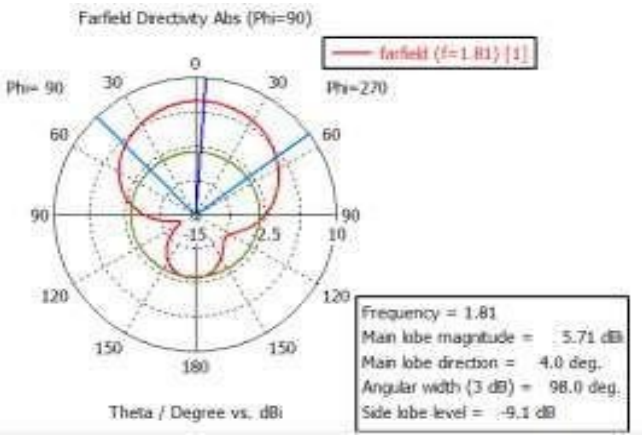

Figure.4.1: Far-field radiation pattern for $1.8 \mathrm{GHz}$

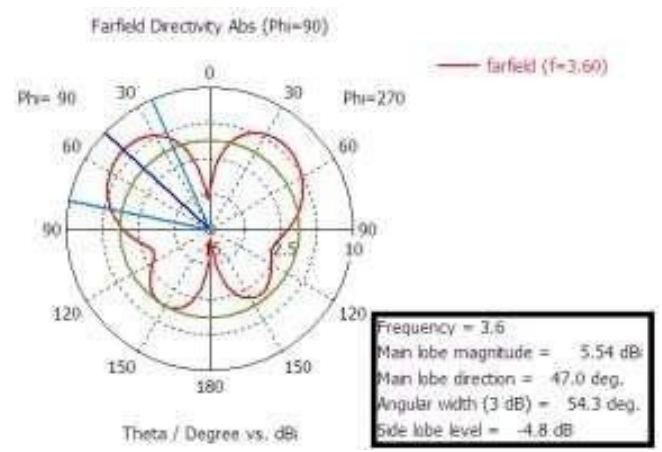

Figure 4.2: Farfield radiation pattern for $3.60 \mathrm{GHz}$.

The radiation pattern shown in figure 4.2 at $3.6 \mathrm{GHz}$ frequency shows the bidirectional nature with angular width 
of $54.3 \mathrm{deg}$. whereas the radiation pattern patterns shown in figures $4.1,4.3 \& 4.4$ shows complete omnidirectional nature with greater angular widths i.e. 98 degrees at 1.81 $\mathrm{GHz}, 61.9$ degrees at $4.53 \mathrm{GHz}$ and 117.8 degrees at 5.73 $\mathrm{GHz}$. Therefore the angular width is reduces when the nature of the radiation pattern is changed from omnidirectional to bidirectional.

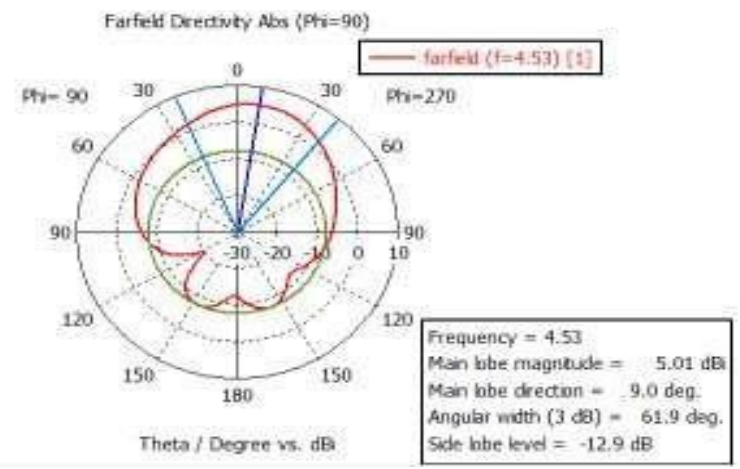

Figure 4.3: Farfield radiation pattern for $4.53 \mathrm{GHz}$.

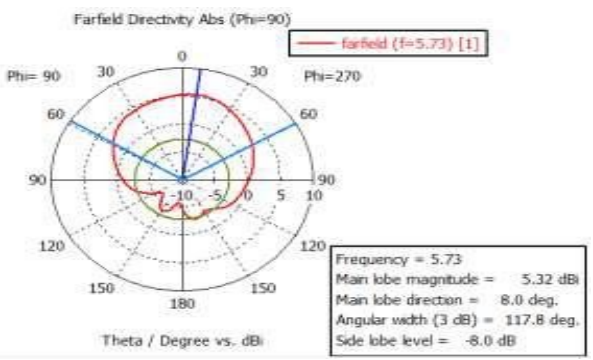

Figure 4.4: Farfield radiation pattern for $5.73 \mathrm{GHz}$.

The radiation pattern shows directivity of $5.71 \mathrm{dBi}$ and main lobe direction of $4.0 \mathrm{deg}$. for $1.8 \mathrm{GHz}$ frequency. The radiation pattern for $3.60 \mathrm{GHz}$ frequency shows directivity of $5.54 \mathrm{dBi}$ and main lobe direction as $47.0 \mathrm{deg}$. The radiation pattern shows directivity of $5.01 \mathrm{dBi}$ and main lobe direction of $9.0 \mathrm{deg}$. for $4.53 \mathrm{GHz}$ frequency. The radiation pattern for $5.73 \mathrm{GHz}$ frequency shows directivity of $5.32 \mathrm{dBi}$ and main lobe direction as $8.0 \mathrm{deg}$. S11, VSWR and directivity of different frequencies are tabulated in table 2 .

Table 2. Return loss, VSWR and directivity of different frequencies

\begin{tabular}{|c|c|c|c|c|}
\hline S.No & $\begin{array}{c}\text { Frequency } \\
(\mathrm{GHz})\end{array}$ & S11(dB) & VSWR & Directivity \\
\hline 1. & $1.81 \mathrm{GHz}$ & $-23.33 \mathrm{~dB}$ & 1.146 & $5.71 \mathrm{dBi}$ \\
\hline 2. & $3.60 \mathrm{GHz}$ & $-28.11 \mathrm{~dB}$ & 1.08 & $5.54 \mathrm{dBi}$ \\
\hline 3. & $4.53 \mathrm{GHz}$ & $-18.86 \mathrm{~dB}$ & 1.25 & $5.01 \mathrm{dBi}$ \\
\hline 4. & $5.73 \mathrm{GHz}$ & $-18.07 \mathrm{~dB}$ & 1.28 & $5.32 \mathrm{dBi}$ \\
\hline
\end{tabular}

The surface current distribution along the antenna at different resonant frequencies is presented in figure 5.

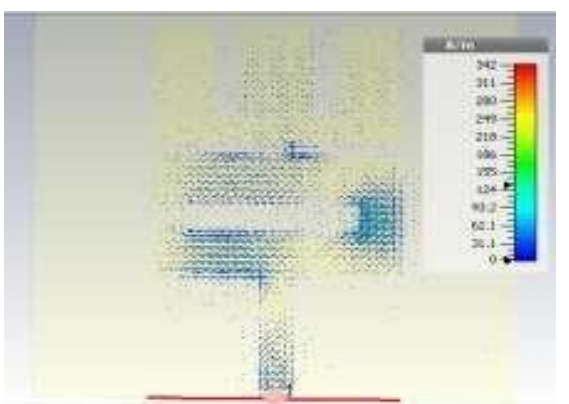

Figure 5.1: Surface current at 1.8GHz.

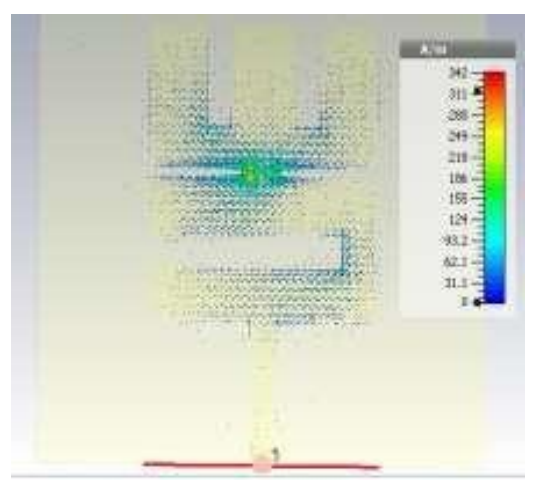

Figure 5.2: Surface current at 3.6GHz.

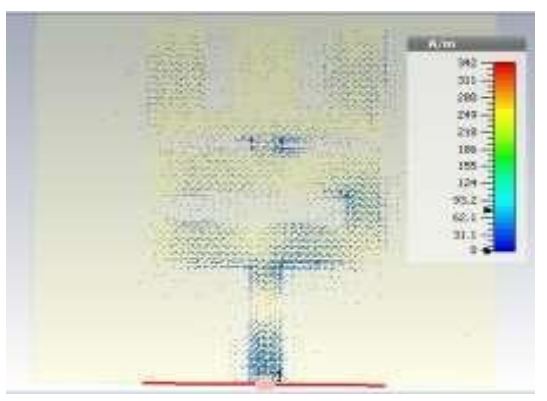

Figure 5.3: Surface current at $4.53 \mathrm{GHz}$.

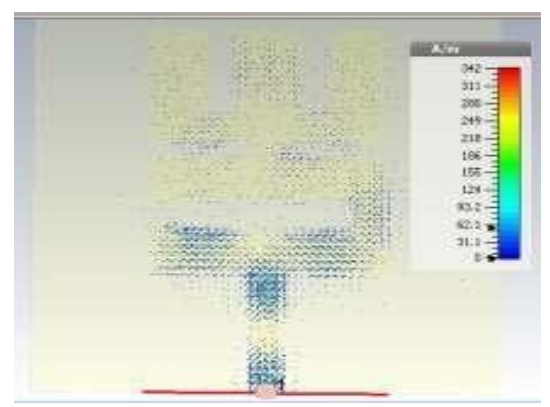

Figure 5.4: Surface current at 5.73GHz.

Different frequencies obtained and their applications are tabulated in table 3 . 
Table 3. Applications for different simulated frequencies

\begin{tabular}{|l|c|c|}
\hline S. No & $\begin{array}{c}\text { Frequency } \\
\text { (GHz) }\end{array}$ & Applications \\
\hline 1. & $1.81 \mathrm{GHz}$ & GSM 1800 \\
\hline 2. & $3.60 \mathrm{GHz}$ & Wi-MAX (IEEE 802.16$)$ \\
\hline 3. & $4.53 \mathrm{GHz}$ & $\begin{array}{c}\text { Used in defense for missile } \\
\text { navigation }\end{array}$ \\
\hline 4. & $5.73 \mathrm{GHz}$ & Wi-Fi/WLAN(IEEE802.11a/h/j) \\
\hline
\end{tabular}

The proposed antenna is fabricated and measured using VNA, the return loss and VSWR measured results are depicted in figure 6 .

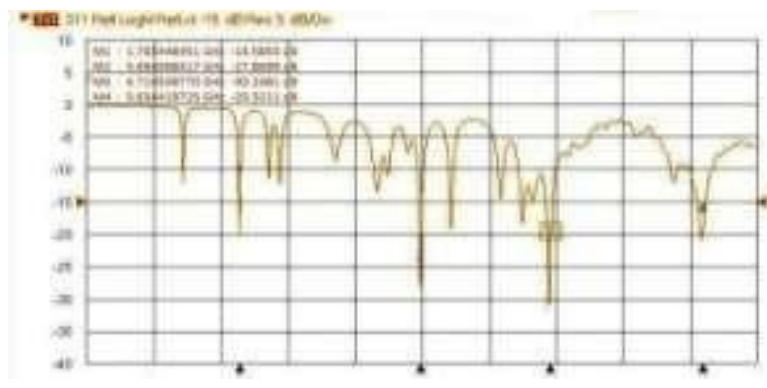

Figure 6.(a): Return loss Experimental result of the

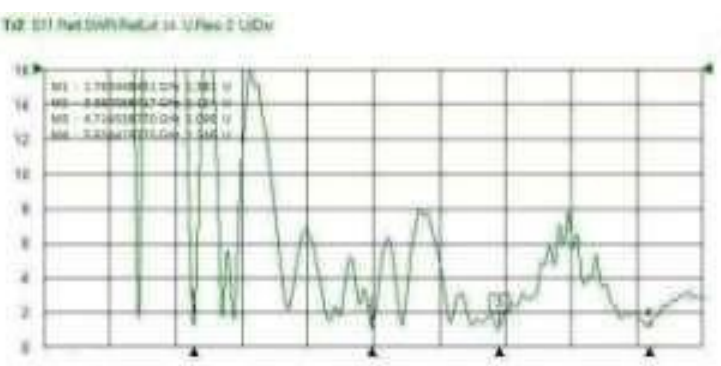

Fabricated antenna using VNA

Figure 6.(b): VSWR Experimental result of the fabricated antenna using VNA

Comparison of simulated results and Experimental results are tabulated in table 4.

Table 4. Simulated results and Experimental results comparison

\begin{tabular}{|l|l|l|l|l|l|}
\hline \multirow{2}{*}{$\begin{array}{l}\text { S. } \\
\text { No }\end{array}$} & \multirow{2}{*}{$\begin{array}{l}\text { Frequency } \\
(\mathrm{GHz})\end{array}$} & \multicolumn{2}{|l|}{ Simulated Results } & \multicolumn{2}{l|}{$\begin{array}{l}\text { Experimental } \\
\text { Results }\end{array}$} \\
\cline { 3 - 6 } & & $\mathrm{S} 11(\mathrm{~dB})$ & VSWR & S11(dB) & VSWR \\
\hline 1 & $1.81 \mathrm{GHz}$ & $-23.33 \mathrm{~dB}$ & 1.146 & -18.58 & 1.381 \\
\hline 2 & $3.60 \mathrm{GHz}$ & $-28.11 \mathrm{~dB}$ & 1.08 & -27.86 & 1.124 \\
\hline 3 & $4.53 \mathrm{GHz}$ & $-18.86 \mathrm{~dB}$ & 1.25 & -30.16 & 1.099 \\
\hline 4 & $5.73 \mathrm{GHz}$ & $-18.07 \mathrm{~dB}$ & 1.28 & -20.32 & 1.246 \\
\hline
\end{tabular}

\section{Conclusion}

A Microstrip patch antenna which can be operated at five different frequencies is designed using CST software and fabricated. The resonant frequencies obtained are $1.8 \mathrm{GHz}$, $3.6 \mathrm{GHz}, 4.5 \mathrm{GHz}, 5.13 \mathrm{GHz}$, and $5.73 \mathrm{GHz}$. This antenna can be used for wireless applications like Wi-Fi, Wi-MAX, GSM1800, and WLAN. Multiband performance is achieved by optimizing the length and width of the patch and by changing the length and width of the slots. Even the locations of the slots also affect the antenna performance. All the frequencies obtained by designing this antenna return loss much lesser than the desired value, i.e. $-15 \mathrm{~dB}$ and also compared with fabricated antenna measured results. For future simulation process, other shapes of slots can be implanted in order to achieve better effect and to cut the antenna size. The increase in bandwidth of the proposed antenna can be increased by utilizing other techniques like photonic band-gap structures and defected ground structures.

\section{References}

[1] C. A. Balanis, Antena Theory, Analysis \& Design, 3rd Edition, Wiley;New York, 2005.

[2] Manisha Gupta, Vinita Mathur "Koch fractal-based hexagonal patch antenna for circular polarization" Turk J Elec Eng \& Comp Sci. 25: 4474 - 4485, 2017.

[3] Guru Prasad Mishra, Madhu Sudan Maharanaa, Sumon Modak, B. B. Mangaraj "Study of Sierpinski Fractal Antenna and Its Array with Different Patch Geometries for Short Wave Ka Band Wireless Applications" $7^{\text {th }}$ ICACC-2017, 2224August 2017, 115, 123-134, 2017.

[4] Shobhit K. Patel, Y.P.Kosta, "E-shape Microstrip Patch Antenna Design for GPS Application.”,International Conference on Current Trends in Technology,Nuicone 2011.

[5] B.K. Ang and B.K. Chung, "A Wideband E-Shaped Microstrip Patch Antenna for5-6GHz Wireless Communications", Progress in Electromagnetics Research, PIER 75, 397-407, 2007.

[6] The Viet Hoang, Tuan Tu Le, Qiu Yu Li and Hyun Chang Park, "Quad-Band Circularly Polarized Antenna for 2.4/5.3/5.8 GHz WLAN and 3.5GHz WiMAX Applications", IEEE Antennas and Wireless Propagation Letters, 1536-1225 (c) 2015 IEEE.

[7] S.Atchaya, N.Dhanalakshmi, R.Veeramani, "A Compact Design of Multiband Microstrip Patch Antenna for GSM, Bluetooth and WiMAX Applications", International Journal of Communication and Computer Technologies. Volume $02-$ No.1 Issue: 04 April 2014.

[8] Radouanekarli, Hassan ammor, "A Simple and Original Design Of Multi-Band Microstrip Patch Antenna for Wireless Communication", International Journal of Microwaves Applications, Volume 2, No.2, March - April 2013.

[9] Dian Wang, Student Member, IEEE and Chi Hou Chan, Fellow, IEEE, "Multiband Antenna for Wi-Fi and WiGig Communications", 1536-1225 (c) 2015 IEEE.

[10] Yinting Liu, Dan Shi, Member, IEEE, Shuyi Zhang, YougangGao, Member, IEEE, "Multiband Antenna for Satellite Navigation System", 1536-1225 (c) 2015 IEEE.

[11] Han-CheolRyu, Hee Ran Ahn, Sang-Hwa Lee and Wee Sang Park, "Triple-Stacked Microstrip Patch Antenna for Multiband System", Electronics Letters 21sr November 2002 Vol. 38 No. 24.

[12] K. Jhamb L. Li K. Rambabu, "Novel-Integrated Patch Antennas with Multi-Band Characteristics", IET Microwaves and Antennas Propagation, 2011, Vol. 5, Iss.12, pp.1393-1398. 